\title{
EL DISCURSO DEL YO: EL ESPIRITUALISMO PSICOLÓGICO EN LA CULTURA ESPAÑOLA DE MEDIADOS DEL SIGLO XIX
}

\author{
Enric J. Novella \\ Université du Luxembourg \\ enric.novella@uni.lu
}

Recibido: 15 diciembre 2012; Aceptado: 17 marzo 2013.

Cómo citar este artículo/Citation: Novella, Enric J. (2013): "El discurso del yo: el espiritualismo psicológico en la cultura española de mediados del siglo XIX”, Asclepio, 65 (2): p016. doi: http://dx.doi.org/10.3989/asclepio.2013.13

RESUMEN: Este artículo ofrece un análisis de la amplia proyección del espiritualismo psicológico en la cultura española de las décadas centrales del siglo XIX. Tras revisar su profundo impacto en el pensamiento filosófico de la época, en la teoría de la medicina y en los discursos en torno a la locura y la responsabilidad criminal, su difusión se interpreta no solo como un intento de reforzar los dogmas tradicionales en torno a la espiritualidad del alma, la unidad de la conciencia o la libertad moral, sino también como la expresión de una cultura que, en líneas generales, todavía no había escindido hechos y valores ni asumido plenamente los presupuestos y las implicaciones más conspicuas de la nueva ciencia positiva y experimental.

PALABRAS CLAVE: Psicología; Espiritualismo; Medicina; Filosofía; España; Siglo XIX.

\section{THE DISCOURSE OF THE SELF: PSYCHOLOGICAL SPIRITUALISM IN MID NINETEENTH-CENTURY SPANISH CULTURE}

ABSTRACT: This paper offers an analysis of the wide projection of psychological spiritualism in Spanish culture during the central decades of the $19^{\text {th }}$ century. After a detailed examination of its profound impact on philosophical thought, medical theory and the prevalent discourses on madness and criminal responsibility, its diffusion is interpreted not only as an attempt to reinforce traditional dogmas concerning the spirituality of the soul, the unity of consciousness or moral freedom, but also as the expression of a culture that, in general terms, had not yet split facts and values nor taken for granted some of the most conspicuous postulates and implications of the new positivist and experimental science.

KEY WORDS: Psychology; Spiritualism; Medicine; Philosophy; Spain; 19th Century.

Copyright: () 2013 CSIC. Este es un artículo de acceso abierto distribuido bajo los términos de la licencia Creative Commons Attribution-Non Commercial (by-nc) Spain 3.0. 
«La atmósfera está impregnada de filosofía: su espíritu nos rodea, nos llena, nos arrastra a todos [...]. Lo cierto es que el porvenir del mundo pertenece a la filosofía y que los que en este terreno venzan, esos vencerán en todos, esos darán la ley a la humanidad»

Gumersindo Laverde (1859, p. 381)

\section{INTRODUCCIÓN}

En una sesión celebrada el 21 de enero de 1856 en el Ateneo de Madrid, Pedro Mata se refería despectivamente al discurso psicológico dominante con el término de "yoísmo", al que calificaba como una doctrina particularmente "falsa y estéril", incapaz de dar "una idea cabal de la razón humana" y generadora de un "divorcio absurdo de la fisiología y la psicología". Los "yoístas" - afirmaba Mata- "han hecho una entidad, el yo, la conciencia, y sobre esta abstracción, sobre esta creación ontológica, quimérica, han fundado una [...] verdadera torre de Babel, donde todos hablan y ninguno se entiende" (Mata y Fontanet, 1858, pp. 47-48). “Así - proseguía al año siguiente en la tercera edición de su influyente Tratado de medicina y cirugía legal- los psicólogos, que parecían deber ser la antorcha que aclarase esta materia, han sido los que más la han embrollado" (Mata y Fontanet, 1857, Vol. 2, p. 170).

Ciertamente, reafirmándose en sus vehementes críticas hacia el espiritualismo psicológico -inspiradas, en su caso, por planteamientos de corte sensualista y nominalista ${ }^{1}$-, el médico catalán no se enfrentaba a un autor o a una escuela filosófica concreta, sino a un amplio y poderoso consenso cultural que, sustentado a partes iguales en los dictados de la tradición y en los valores emergentes de la nueva sociedad burguesa, marcó el despliegue y el rumbo del discurso filosófico en España durante buena parte del siglo XIX (Heredia Soriano, 1989, pp. 369-398). Prescindiendo de los matices aportados por sus numerosos expositores, los presupuestos centrales de esta ortodoxia espiritualista se sustanciaron en una serie relativamente invariable de axiomas, entre los que destacan (1) la afirmación del 'yo' como una instancia unitaria, idéntica e inmaterial y un 'hecho primitivo' previo e independiente de la sensación, (2) el énfasis en la conciencia como un dominio legítimo de experiencia accesible por medio de la introspección y (3) la ecuación del psiquismo con el 'esfuerzo voluntario', esto es, la atribución al 'yo' de un carácter activo y causalmente eficaz.

A España, esta psicología llegó a partir de la década de 1830 de la mano de la filosofía escocesa del 'sentido común' - especialmente en el ámbito catalán (Guy, 1985, pp. 241-244) - y, sobre todo, de la Ideología espiritualista y la escuela ecléctica francesa comandada por Victor Cousin (Carpintero, 2004, pp.
64-67), la cual, por su notoria afinidad no solo con los dogmas tradicionales en torno a la espiritualidad del alma, la unidad de la conciencia o la libertad moral, sino también con la visión del mundo, la autocomprensión y los intereses de las nuevas elites liberales - tan propensas a concebir su creciente influencia en términos de mérito, esfuerzo y contención moral (Villacorta Baños, 1993, pp. 161-173; Serrano García, 2001, pp. 93-99) - , se convirtió en una parte muy sustancial de la filosofía enseñada a partir de entonces en las universidades e institutos de enseñanza media de todo el país (Heredia Soriano, 1982; Novella, 2012).

Pero, aparte de erigirse en el elemento nuclear de la cultura filosófica de las décadas centrales del siglo XIX y en la punta de lanza para la refutación de doctrinas que, como el sensualismo, la frenología o el magnetismo animal, habían gozado de un cierto predicamento y difusión durante la primera mitad de la centuria, el espiritualismo psicológico también tuvo un profundo impacto en la teoría médica y en los discursos en torno a la locura y la responsabilidad criminal, demorando notablemente la progresión de una aproximación abiertamente determinista al estudio de la actividad psíquica y la conducta desviada. No por casualidad, su hegemonía y su asunción mayoritaria por parte de los sectores instruidos de la sociedad se dio en un periodo en el que otras teorías y disciplinas que -como el darwinismo, la paleontología, la anatomía comparada o la embriología - implicaban un fuerte cuestionamiento de la imagen del ser humano sostenida por la tradición, fueron objeto de intensas controversias e incluso inspiraron diversos intentos de 'conciliación' por parte de los científicos españoles (Pelayo, 1999).

En el presente trabajo, me propongo evaluar con cierto detalle la proyección cultural de todo este entramado doctrinal en la España de mediados del siglo XIX, tratando de mostrar la amplia repercusión del mismo no solo en el ámbito estricto del pensamiento filosófico, sino en el conjunto de la vida intelectual y científica del país en un periodo en el que esta experimentó un lento pero notable proceso de desarrollo y afianzamiento tras las convulsiones que marcaron el colapso del Antiguo Régimen y el accidentado tránsito hacia el nuevo orden liberal (Abellán, 1984, pp. 535555; López Piñero, 1992). Con este objetivo, trazaré primero una panorámica general de las líneas maestras de la producción filosófica española en las décadas de 1850 y 1860 tal como quedó consignada en una 
serie de obras emblemáticas y en diversas publicaciones de índole divulgativa. Posteriormente, esbozaré un análisis más detenido del profundo impacto de las tesis espiritualistas en las reflexiones teóricas de un buen número de médicos españoles, entre quienes promovió el cultivo de una especulación filosófica muy alejada del incipiente positivismo y experimentalismo de la ciencia europea del momento y condicionó notablemente la recepción de importantes novedades clínicas y conceptuales. Y, por último, valoraré las resistencias y el papel de contención desempeñado por el ideario espiritualista frente a la introducción de las nuevas corrientes de pensamiento psicológico que irrumpieron en el país a partir de la década de 1870 , a las que algunos autores de diversas filiaciones no dudaron en calificar como particularmente perniciosas y disolventes de los más altos principios de la civilización y el orden moral. Como veremos, el discurso psicológico, que había estado dominado durante décadas por un consenso relativamente amplio que empezaba a resquebrajarse por la creciente pujanza de corrientes o prácticas tan dispares como la psicología fisiológica primero y el hipnotismo después, se erigió así en uno de los escenarios centrales en los que se dirimieron algunas de las disputas y debates más enconados que acompañaron el despliegue de los presupuestos y las implicaciones más conspicuas de la nueva ciencia positiva y experimental.

\section{EL ESPIRITUALISMO COMO HORIZONTE}

Tal como ha señalado Antonio Heredia, no cabe duda de que el espiritualismo "constituye la tendencia filosófica más genuina de la época isabelina", una tendencia que, aparte de ser sancionada oficialmente por medio de su rápida infiltración en los contenidos transmitidos por el sistema educativo, se presentó como un "amplísimo movimiento restaurador [...] movido por intereses fundamentalmente morales, políticos y religiosos" (Heredia Soriano, 1989, p. 379). Articulado de forma paradigmática en los laxos postulados del sensualismo 'mitigado' y, sobre todo, de la escuela ecléctica francesa, el espiritualismo se erigió así - al menos inicialmente- no tanto como un corpus teórico y doctrinal más o menos definido (como pone de manifiesto la amplia heterogeneidad de los autores que militaron en sus filas), sino más bien como una tendencia esencialmente renovadora que anunciaba otro "modo de filosofar: ecléctico y conciliador, tolerante y moderado, opuesto al dogmatismo y al espíritu de sistema, basado en la reflexión personal y en diálogo abierto con la historia de la filosofía", hasta el punto de representar "una fuerza generadora de primer orden que llegó a impregnar toda la vida cultural del período" (Heredia Soriano, 1989, p. 379).

Dejando de un lado por el momento la aparente contradicción en que incurre Antonio Heredia al cali- ficarlo como un movimiento simultáneamente restaurador y renovador, de lo que no hay duda es de que, en un sentido amplio, el espiritualismo constituyó el horizonte intelectual en el que se desenvolvió el grueso de la producción filosófica española en las décadas de 1850 y 1860 . Y, en este sentido, es muy revelador que su presencia se hiciera notar no solo en los trabajos más o menos originales de una extensa nómina de autores entre los que descuellan Patricio de Azcárate, Ramón de Campoamor o Nicomedes Martín Mateos, sino también en las secciones dedicadas a la filosofía o la psicología aparecidas puntualmente en las numerosas publicaciones de carácter enciclopédico o divulgativo que circularon en aquellos años por el país.

En 1853, el abogado y político leonés Patricio de Azcárate (1800-1886), que en los últimos años de su vida realizaría una ingente labor como traductor de las obras de Platón, Aristóteles y Leibniz², dio a la imprenta unas Veladas sobre la filosofía moderna en cuyo prólogo advertía enfáticamente de la finalidad de su empeño y la filiación de sus ideas:

La filosofía del plan de estudios vigente, sin elevación y sin dignidad, es la filosofía de la materia; y materializada la ciencia no sé cómo deje de materializarse la sociedad. Y el español, que es espiritualista por instinto, por raza, por elevación de sentimientos y por sus creencias religiosas, ¿es acreedor a que se le inocule en estas tendencias empíricas y se desnaturalice su carácter? (Azcárate, 1853, p. 12).

De acuerdo con la tendencia de la época, Azcárate presentaba el espiritualismo, o lo que él denominaba "sistema psicológico", como un movimiento filosófico que, arrancando en la llustración escocesa y consolidándose en la Francia de la primera mitad del siglo XIX, había conducido a superar los escollos respectivos y opuestos del sensualismo o "sistema empírico" (el materialismo) y del racionalismo o "sistema idealista" (el panteísmo). Y, tal como explicaba años más tarde en su Exposición histórico-crítica de los sistemas filosóficos modernos y verdaderos principios de la ciencia, solo el sistema psicológico, esto es, el "estudio del yo por medio de la observación interna" y la constitución correlativa de una verdadera "ciencia del alma" podían proporcionar un cimiento sólido y duradero para la reflexión filosófica:

Es tan necesario el estudio del alma como el punto de partida para hacer progresos en todo el campo de la

filosofía, que no hay rama de los conocimientos humanos que no descanse en ciertos hechos y ciertos principios que solo la observación psicológica puede darnos (Azcárate, 1861, Vol. 1, p. 22).

En su rigor espiritualista, Azcárate llegaba a criticar al mismo Cousin por haberse extraviado ocasionalmente en las "marcadas tendencias al panteísmo de los filósofos alemanes" (Azcárate, 1861, Vol. 4, p. 61), así como por la extrema ambigüedad e inconsistencia 
doctrinal del eclecticismo, al que no dudaba en calificar como "la tumba de todos los sistemas filosóficos" y como un "absurdo de los tiempos modernos" (Azcárate, 1861, Vol. 4, p. 62 y pp. 78-79). Y, por ese motivo, expresaba una mayor sintonía con los planteamientos del discípulo de Cousin, Theodore Jouffroy, el cual, dotado de un gran talento para la observación interior y un finísimo sentido para consignar las particularidades de los diversos estados psíquicos, había contribuido a su juicio en mucho mayor grado al verdadero desarrollo del "sistema psicológico" (Azcárate, 1861, Vol. 4, pp. 68-74).

Por su parte, el polifacético hombre público y de letras Ramón de Campoamor (1817-1901) publicaba en 1855 El personalismo, una de sus obras filosóficas más conocidas a pesar de no contener una exposición sistemática ni excesivamente coherente de sus ideas. En este sentido, cabe anotar que Mario Méndez Bejarano, tras confesar que nunca le había tomado muy serio como filósofo, no vaciló en afirmar que "en el espíritu de Campoamor se mezclan todos los sistemas, fe y escepticismo, idealidad y burla, lo propio y lo ajeno, para que resulte un filósofo en verso y un poeta en prosa" (Méndez Bejarano, 1929, p. 511). De hecho, su producción filosófica ha sido vinculada tanto al idealismo alemán (Bueno, 2003, pp. 9-13) como al espiritualismo cristiano (Heredia Soriano, 1989, p. 383), aunque una lectura atenta de El personalismo cuestiona estas filiaciones - al menos en un sentido estricto- y revela, eso sí, una línea de pensamiento divagatoria y poco consistente que, en todo caso, puede calificarse como un espiritualismo bastante convencional con algún que otro conato idealista ${ }^{3}$. Sea como fuere, lo cierto es que no resulta difícil encontrar en El personalismo toda una serie de lugares comunes de la ortodoxia espiritualista, como en este fragmento preliminar en el que Campoamor se explaya sobre la unidad, la espiritualidad y la identidad del 'yo':

Esta unidad concienciosa del yo, síntesis de todo lo sensible y de todo lo inteligente, centro invisible donde se confunden todos los sentimientos y todas las ideas, es una substancia simple, inanalizable, inmaterial; es un ser único, que no admite división ni interrupción ni duplicidad, que en sí y fuera de sí es idéntico hasta la mas perfecta identidad (Campoamor, 1855 , pp. 17-18, cursivas en el original).

En las antípodas de Campoamor en cuanto a sobriedad y solidez cabe destacar, por último, las aportaciones del filósofo de Béjar Nicomedes Martín Mateos (1806-1890), que ya en 1853 había remitido al Ministro de Gracia y Justicia unas Breves consideraciones sobre la reforma de la filosofía en las que, en unos términos muy similares a los de Azcárate, advertía alarmado que "cuantos libros sirven hoy de texto en las cátedras de filosofía conducen al panteísmo, al mate- rialismo o al idealismo" (Martín Mateos, 1853, p. 10). Tempranamente adscrito al partido progresista pero muy influido por el neocartesianismo del pensador católico francés Jean-Baptiste Bordas-Demoulin -con quien llegó a mantener una relación epistolar directa (Jiménez García, 1992)-, Martín Mateos publicó entre 1861 y 1863 un curso de filosofía en cuatro volúmenes que tituló de forma bien directa: El espiritualismo. Dividido en cinco secciones (metafísica, fisiología, lógica, moral y teodicea), el curso contiene una extensa exposición de la "verdadera filosofía espiritualista", esto es, de aquella que, arrancando en Platón y pasando por San Agustín, culmina en las obras de Descartes, Leibniz o Bossuet y encuentra en Bordas una síntesis a la altura de su tiempo. De acuerdo con el psicologismo de la época, Martín Mateos define esta filosofía como "la ciencia de nuestros medios de conocer, [...] la única que puede suministrar la certidumbre de los conocimientos y la única que presta a los pueblos y a los individuos la templanza, la fe, la actividad y el progreso pacífico" (Martin Mateos, 1861, p. 32). Pero, para tan alto empeño, el filósofo "solo cuenta con la ciencia del estudio del alma, de sus facultades y de las leyes que presiden su desarrollo"; una ciencia, en suma, cuyo método no es sino el del recogimiento interior y la reflexión paciente y sistemática, de manera que "mi alma pueda contemplar su propia vida en esa generación incesante de ideas que constituye la fecundidad de mi pensamiento" (Martín Mateos, 1861, p. 33). Y "en esta contemplación - concluye- veré en mí un ser inmaterial, en el que todo es espontaneidad, concepción, evolución, multiplicidad en la unidad, y por consiguiente vida espiritual" (Martín Mateos, 1861, p. 436). Igualmente, solo por este camino puede el filósofo satisfacer su "misión social", pues, dado que la "enfermedad de la humanidad es espiritual, [...] para curarla es indispensable intervenir en el mundo interno del alma" (Martín Mateos, 1861, p. 440). Y, en este sentido, no debe sorprender que Martín Mateos - para quien, como el propio Descartes, el alma humana se sostenía ontológicamente merced al influjo y la dependencia constante de Dios - viera justamente en la conciliación del "espíritu moderno y el espíritu cristiano [...] la gran cuestión del siglo" y la enseña misma de todo su proyecto filosófico (Albares Albares, 2005, p. 200).

En cualquier caso, ya he señalado anteriormente que la difusión del pensamiento espiritualista no se limitó a la obra teórica de un grupo más o menos definido de autores, sino que sus postulados infiltraron por completo las secciones dedicadas a la filosofía en diversas publicaciones de carácter enciclopédico o divulgativo, de manera que la misma naturaleza de estas obras les tendía así a conferir un carácter de conocimiento probado o establecido. De este modo, por ejemplo, la entrada "Alma" de la Enciclopedia Española del Siglo Diez y Nueve iniciada por el editor Ignacio 
Boix - que solo llegó a completar los artículos correspondientes a la letra $A-$ no vacilaba en afirmar que:

a excepción de algunos espíritus soberbios que para hacerse un nombre tuvieron en poco la ventura del género humano, y de varias hordas salvajes rebajadas al instinto de los brutos, todas las naciones han reconocido en el hombre una sustancia independiente del cuerpo y fuente de la voluntad y de la inteligencia ${ }^{4}$.

Igualmente, y a pesar de no contener una entrada específica para la psicología, la importante Enciclopedia Moderna auspiciada por el prolífico Francisco de Paula Mellado, que fue el primer proyecto de este tipo completado en España con 34 volúmenes publicados entre 1851 y 1855, ofrecía en sus artículos "Alma", "Espíritu” y "Materialismo" una suerte de compendio del espiritualismo psicológico en el que se sintetizaban todos y cada uno de sus principales axiomas. El artículo "Alma", por ejemplo, planteaba en los siguientes términos el dogma imperecedero de su espiritualidad:

El hombre puede, pues, existir de otro modo que con órganos; pues que tiene ideas y pensamientos que no participan nada de orgánico, y pues que en él posee, el ser inteligente, una esfera de actividad en la cual no está encerrada la vida del ser material ${ }^{5}$.

Por su parte, la entrada "Espíritu" definía la psicología en el sentido cartesiano de una "ciencia del alma" cuyos fundamentos residían en la validez e inmediatez de los fenómenos ofrecidos por la conciencia, y cuya actividad o eficacia causal constituía la única garantía de la auténtica libertad y responsabilidad moral:

Lo que entendemos por espíritu en contraposición con la materia comprende todo lo que es del dominio de la inteligencia, de la imaginación y de la moral. He aquí que la palabra espíritu abraza toda la psicología. [...] El espíritu es una parte constitutiva, la base superior de las facultades del hombre: su existencia es para este un hecho de conciencia, de donde resulta la moralidad, la atribución y la responsabilidad de sus actos. [...] Todo hombre se conoce a sí mismo, y puede, por lo tanto, decir con razón yo soy una sustancia: supone también por analogía una sustancia en el cuerpo o en la materia, sin comprender lo que es, y sin tener idea clara de una sustancia inmaterial; de lo que se deduce que la idea del espíritu es clara, natural y fundada en el sentimiento interior, y la de la materia es oscura, ficticia, y fundada sobre la primera ${ }^{6}$.

Y, finalmente, el artículo "Materialismo" calificaba consecuentemente esta doctrina como un "absurdo" particularmente abyecto que "disuelve los vínculos sociales y desencadena las pasiones mas brutales", de manera que solo podía considerársele como un "delirio de imaginaciones enfermas" frente al que cualquier "entendimiento sano y espíritu recto" debía alzarse blandiendo la incuestionable soberanía del 'yo':
Creemos que basta la simple exposición de este sistema para producir en toda conciencia humana un sentimiento de voluntad, de espontaneidad, de poder autocrático que protesta contra una abnegación tan servil, que nos enseña nuestra libertad moral, y que nos dice que podemos luchar contra la tiranía y la muerte, y disfrutar de nuestra independencia. Este yo siempre revela algo de superior y de dominante sobre la materia?.

Haciéndose eco de la creciente demanda de obras más accesibles, el mismo Mellado editó en 1851 con el título de Instrucción para el pueblo una colección de "cien tratados sobre los conocimientos más indispensables" en la que también se incluían unas "Nociones generales de filosofía" redactadas por el agregado de la Universidad de Madrid Remigio Ramírez. Y, como es de suponer, también en ellas se presentaba la psicología como la disciplina que "nos da a conocer las cualidades del alma humana", se definía a la conciencia como la "luz interior" del alma, se justificaba la tradicional división de esta en las facultades del "sentir, entender y querer", y se argumentaba a favor de su inmortalidad en unos términos tan grandilocuentes como significativos:

Si fuese verdad que el alma del hombre es material, y que ha de perecer con el cuerpo, esta sería una verdad muy triste y muy humillante para la humanidad. [...] Pero no se crea que la inmortalidad del alma se funda en meros presentimientos o en motivos de interés; otras pruebas más sólidas la ponen de manifiesto. La fe de las naciones, las apoteosis de sus héroes, la persuasión general del género humano, la naturaleza espiritual del alma, las ideas que tenemos de Dios, su providencia, su justicia, su bondad y los inconvenientes de la opinión contraria, son otras tantas pruebas de la inmortalidad del alma (Ramírez, 1851, col. 1758).

Teniendo en cuenta todos estos testimonios, parece pues evidente que la difusión del espiritualismo psicológico en la España del segundo tercio del siglo XIX no constituyó un fenómeno que pueda interpretarse como una mera circulación de ideas o corrientes de pensamiento, sino que apunta inversamente a la presencia de un ubicuo consenso cultural que condicionó a su vez el grueso de la producción filosófica de la época. Ciertamente, la inspiración doctrinal proporcionada por el eclecticismo francés fue perdiendo fuelle con el tiempo y, de hecho, a partir de la década de 1860 el panorama filosófico se vio crecientemente dominado por la contraposición entre el racionalismo krausista y el neocatolicismo tomista (Heredia Soriano, 1989, pp. 383-398), corrientes ambas que desde un principio mostraron una actitud muy desdeñosa y crítica con el espiritualismo de raigambre cousiniana. Así, por ejemplo, en un discurso pronunciado en 1861 
en el Ateneo de Madrid, Francisco de Paula Canalejas, catedrático de literatura y discípulo de primera hora de Julián Sanz del Río, consideraba ya el eclecticismo como una doctrina totalmente estéril y periclitada, aunque no dejaba de reconocer que su influencia en la vida intelectual española seguía siendo más que notable, pues "con traducciones y paráfrasis de escritores eclécticos se alimentó a nuestra juventud, y bien puede sostenerse que aún posee esta doctrina la mayor parte de la inteligencia de nuestra sociedad, así como ha creado nuestras costumbres y nuestros sentimientos" (Canalejas, 1861, pp. 9-10).

Por su parte, los autores neocatólicos, con Juan Manuel Ortí y Lara, el Padre Zeferino González y —-más tarde-Marcelino Menéndez Pelayo a la cabeza, no dejaron de denunciar el psicologismo y el panteísmo que, a su juicio, lastraba la filosofía de Cousin ${ }^{8}$. El Padre González, por ejemplo, censuraba particularmente la pretensión de este último de "asentar el edificio de la ciencia humana sobre la base ruinosa y exclusiva de la psicología, esforzándose en deducir la enciclopedia toda de los conocimientos humanos de un hecho singular y una modificación psicológica" (González, 1864, p. 116). Pero, como ya he mostrado en un trabajo anterior (Novella, 2010), muchos docentes krausistas y neocatólicos respetaron durante años los contenidos de unos programas oficiales que suponían una herencia más o menos directa del espiritualismo ecléctico, cuya presencia en la producción filosófica española, por lo demás, se prolongó hasta el Sexenio y más allá merced a la actividad de los autores ya citados y de otros como Gumersindo Laverde, José Moreno Nieto, Francisco de la Pisa Pajares, Manuel Alonso Martínez o el mismísimo Antonio Cánovas del Castillo (Heredia Soriano, 1989, pp. 412-413). En síntesis, pues, y como bien advirtió Canalejas, el espiritualismo psicológico - como elemento nuclear y más popular del eclecticismo y otras escuelas afines - todavía dominaría durante un tiempo "la inteligencia, las costumbres y los sentimientos" de un gran número de españoles instruidos.

\section{MEDICINA, FILOSOFÍA Y ORDEN MORAL}

Entre los diversos sectores de la "inteligencia" nacional, las tesis espiritualistas gozaron de una llamativa infiltración y popularidad en las reflexiones teóricas de los médicos españoles. Frecuentemente acusados de asumir y propagar con sus doctrinas las perniciosas semillas del sensualismo y el materialismo o de constituir una poderosa avanzadilla de los presupuestos más controvertidos de la ciencia moderna ${ }^{9}$, lo cierto es que un sector mayoritario de la profesión abrazó en las décadas centrales del siglo XIX el espiritualismo (y otras doctrinas afines como el vitalismo) no solo como un eco diferido de las propuestas de una serie de médicos católicos franceses cuyas obras circularon ampliamente en España a lo largo de la década de $1840^{10}$, sino como una consecuencia directa del clima filosófico e intelectual imperante en el país. De este modo, las publicaciones médicas de la época abundan en todo tipo de escritos de filiación espiritualista en los que se censuraban airadamente las posiciones organicistas asociadas a corrientes como la Ideología, el sensualismo, el brusismo o la frenología, a la vez que promovían un género de reflexión teórica sobre la disciplina que hacía gala de un carácter abiertamente especulativo.

Junto al catedrático de obstetricia y médico de cámara de Isabel II Tomás del Corral y Oña -que en 1869 daría a la imprenta una Historia de la filosofía médica de clara inspiración vitalista-, uno de los cultivadores más señalados de esta "filosofía médica" fue, sin duda, el médico palentino Matías Nieto y Serrano (1813-1902), director de revistas médicas tan emblemáticas como la Gaceta Médica (1845-1853) o El Siglo Médico (1854-1936) y secretario perpetuo de la Real Academia de Medicina de Madrid a partir de 1861. En uno de sus primeros escritos, publicado precisamente en el primer número de El Siglo Médico, Nieto lamentaba la "anarquía" en la que a su juicio se encontraba la "filosofía médica especulativa" debido a la "superabundancia de sectas", pero, sobre todo, a la problemática orientación general de la "medicina práctica",

que, sin saberlo ella misma, se ha dejado dominar demasiado por las teorías organicistas, que si las más de las veces solo le sirven de explicación más o menos feliz, algunas la arrastran, sobre todo en manos atrevidas o imprudentes, más allá del punto donde le convendría detenerse (Nieto y Serrano, 1854, p. 2).

A partir de esta declaración de principios, Nieto se dedicó en los años siguientes a presentar en diversas obras como el Ensayo de medicina general (1860), La reforma médica (1863) y, sobre todo, el Bosquejo de la ciencia viviente (1867), una reelaboración crítica de los fundamentos de la medicina y la biología en la que es notoria la influencia general del vitalismo, el idealismo alemán (particularmente el neocriticismo del filósofo francés Charles Renouvier) y la Naturphilosophie romántica (Riera, 1977). Pero, como él mismo reconocería más tarde en sus memorias, el impulso inicial para su empresa filosófica no lo proporcionó sino su contacto precoz con el espiritualismo francés:

La detenida lectura de las obras de Cousin, además de algunas otras que no es del caso mencionar, influyó en mi ánimo, apartándome de todo sistema exclusivo. Obtuve con esto la ventaja de librarme del materialismo exclusivo y recobrar mi libertad de acción (Nieto y Serrano, 1902, p. 245).

$Y$ este trasfondo espiritualista es bien patente no solo en sus diversos escritos sobre la locura o la liber- 
tad moral (a los que más adelante me referiré), sino muy especialmente en las (literalmente) interminables polémicas que libró con Pedro Mata.

Como ya hemos apuntado, Mata fue uno de los escasos autores de relieve que mantuvo viva en aquella época la ambición de fundar el estudio del psiquismo sobre presupuestos estrictamente fisiológicos, lo que unido a su acusada vehemencia y fogosidad intelectual, le convirtió en el blanco preferente de las críticas de la mayoría espiritualista. El propio Nieto fue el encargado de abrir las hostilidades en El Siglo Médico con una reseña del Tratado de la razón humana de Mata en la que atacaba duramente sus ideas por conducir a una negación completa de la espiritualidad del alma, la unidad de la conciencia y la responsabilidad moral:

Cuando se renuncia al yo para entronizar exclusivamente a la naturaleza, nada más legítimo que rechazar todo estudio sintético, todo análisis racional, para fijarse solo en el análisis empírico, concediéndole una importancia exagerada. Pero la fisiología y la psicología tienen terrenos muy distintos y bien deslindados, y toda invasión de la una respecto de la otra debe considerarse como un abuso. [...] Se fracciona al individuo, se le divide y subdivide, olvidando tal vez que no por eso deja de ser uno e indivisible; se sustituye la anarquía a la monarquía natural de su organismo; se le distribuye en potencias, y se las hace funcionar aisladamente. [...] iDébil apoyo concedido a esa libertad que se halla tan arraigada en la conciencia humana, a esa libertad [...] que proclama a gritos su autocracia en todos los momentos y en todas las determinaciones del ser inteligente! (Nieto y Serrano, 1858, pp. 409-410, cursivas en el original).

Mata replicó entonces con una serie de cartas en las que rechazaba frontalmente las apreciaciones de Nieto (y, muy especialmente, el cargo de materialismo), aunque no desaprovechaba la ocasión para criticar severamente el vitalismo, cuestionar la naturaleza sustancial del 'yo' y reafirmar el necesario "consorcio" de la fisiología y la psicología:

Llevamos muchos siglos de vitalismo de todos los trajes y calibres, y estamos hoy como en los primeros tiempos, al paso que con pocos años de aplicación de la física y de la química a la fisiología ya se ha rasgado el velo del misterio respecto de muchos fenómenos vitales que el pretencioso vitalismo no ha sabido nunca esclarecer. [...] Mire usted el yo, no como una entidad fantástica absurdamente indivisible, cual lo han hecho los yoístas, sino como una voz de sentido colectivo que representa el cuerpo y alma de cada cual, como un pronombre según ha sido siempre en la gramática. [...] Lejos de confundir la fisiología con la psicología, lejos de anular a esta de una plumada como usted tan sin razón supone, hemos de dar a cada ciencia lo que le corresponde, y probar prácticamente que el divorcio establecido entre lo físico, lo moral y lo intelectual por ciertas escuelas es el mayor de los absurdos (Mata y Fontanet, 1859a, pp. 12, 39 y 83, cursivas en el original).
Visiblemente irritado, Nieto se apresuró a reiterar sus puntos de vista en una nueva serie de cartas en las que negaba a Mata cualquier originalidad filosófica y reducía su figura a la de un mero "expositor, más o menos afortunado, del materialismo" (Nieto y Serrano, 1859).

Pero, en esos momentos, Mata ya se había embarcado en una nueva y sonada polémica tras pronunciar el 16 de enero de 1859 en la Real Academia de Medicina de Madrid un provocativo discurso sobre Hipócrates y las escuelas hipocráticas en el que relativizaba su papel como genio fundador de la medicina occidental y, sobre todo, denunciaba su apropiación espuria por parte de la "reacción vitalista" del momento:

Era de ver que, resucitado en el mundo filosófico el espiritualismo y evocadas las sombras de Pitágoras, de Platón y de Descartes, había de resucitar también, en las ciencias médicas, el vitalismo, y evocarse igualmente las sombras de los Stahl, de los Bordeu y los Barthez, y como quiera que haya habido muchos vitalismos, a cual más estrambóticos y desacreditados, era una necesidad vestir al del siglo XIX con alguna túnica sagrada o venerable. De aquí la restauración del hipocratismo y la evocación de la doctrina de Hipócrates, la que, gracias a una negación completa de lógica y espíritu analítico, se considera por los medios hipocratistas como el polo opuesto al materialismo en filosofía y fisiología (Mata y Fontanet, 1859b, p. 8).

Tal como la calificaron sus adversarios, la "brusca e intempestiva" intervención de Mata levantó las ampollas esperables en el bando espiritualista y vitalista, acaparando la atención de los académicos a lo largo de un total de 18 extenuantes sesiones en las que el catedrático de medicina legal y toxicología contendió - con gran repercusión pública - con la flor y nata de los médicos de la corte (Ramos, 1954). Entre estos se significaron especialmente los catedráticos de la Universidad Central Tomás Santero, Juan Castelló, José Calvo y Martín, Francisco Alonso y Juan Drumen, quienes, secundados por el higienista Francisco Méndez Álvaro y el propio Nieto, publicaron conjuntamente ese mismo año sus sentidos discursos en Defensa de Hipócrates, de las escuelas hipocráticas y del vitalismo, mientras El Siglo Médico, La España Médica y la parisina Revue Médicale (conocida justamente por su filiación vitalista) acogían en sus páginas las adhesiones de otros médicos eminentes como Pedro Felipe Monlau, Anastasio Chinchilla, José Varela de Montes y el sevillano Manuel de Hoyos Limón (autor de un voluminoso estudio sobre el Espíritu del hipocratismo en su evolución contemporánea aparecido unos años antes). Inaccesible al desaliento, Mata replicó uno a uno a sus impugnadores y mantuvo una agria disputa con El Siglo Médico que relató con gran apasionamiento en un volumen cercano al millar de páginas que publicó al año siguiente, en el que compiló todas sus intervenciones en la "gran discusión" y reprodujo 
las numerosas cartas de apoyo que había recibido de parte de sus seguidores (Mata, 1860).

Con motivo de la aparición en abril de 1861 de El Pabellón Médico, una revista editada y dirigida por el farmacéutico madrileño Félix Borrell y muy cercana a las posiciones de Mata, Nieto volvió a la carga con una serie de artículos en los que tomaba el programa de esta publicación como un caso ejemplar de su denostado "materialismo médico"11, para el cual "el espíritu, el alma, la vida, la sensación y el conocimiento son cosas vanas, o por mejor decir no son cosa alguna" (Nieto y Serrano, 1862, p. 817). Mata respondió de inmediato desde las mismas páginas de El Pabellón censurando la "pertinacia casi frisante en monomanía" de su adversario y el carácter dogmático y especulativo de sus escritos, declarándose "harto de fraseología platónico-aristotélica, empachado de abstracciones y ontologías, ahíto de cuestiones teológicas y metafísicas y hastiado de dimes y diretes palabreros" (Mata, 1863a, p. 29). A los pocos días, Nieto replicó en El Siglo Médico rebajando el tono y diciendo que no había sido su propósito "salir al paso de la escuela físico-química", sino solo "completarla en lo tocante a la filosofía por el mismo camino que ha seguido toda la escuela filosófica moderna" (Nieto y Serrano, 1863a, p. 65).

Como pronto veremos, Mata y Nieto todavía se enzarzaron durante esos años en una nueva discusión a cuenta de la cuestión crucial de la "libertad moral", pero, dentro de los críticos acérrimos del primero (entre los que se contaron también autores no médicos como el propio Campoamor y Francisco Navarro Villoslada), cabe destacar por ahora la singular figura del médico, erudito y polígrafo barcelonés José de Letamendi (1828-1897), el "don Quijote de la lucha contra el positivismo" (Carreras y Artau, 1952, p. 131). Como discípulo de Xavier Llorens i Barba, Letamendi se formó filosóficamente en la órbita de la escuela catalana del 'sentido común' y, antes de perfilar su proyecto de una "antropología integral" y de acometer en las décadas de 1880 y 90 sus obras de madurez ${ }^{12}$, pronunció varios discursos en los que es evidente su militancia de primera hora en las filas espiritualistas. Así, por ejemplo, en el Discurso sobre los elementos generales de ciencia con aplicación al método en medicina (1866), Letamendi afirmaba rotundamente el carácter fundamental para la ciencia de la distinción entre materia y espíritu:

Lo que la realidad de la naturaleza nos impone es el Dualismo Real; esto es, pues, lo que aceptamos, a saber: la totalidad de los objetos observables, dividida substancial y formalmente en dos especies: una espiritual y otra material: la primera, revelada a sí misma en el hecho de conciencia (mundo psicológico); y la segunda percibida por el espíritu a favor de los sentidos externos, como un ser claramente distinto de él (mundo material). La imposición del asenso al Dualis- mo Real viene de una fuerza superior a la razón humana; toda cuestión de pretensiones científicas sobre este particular es fútil, absurda y petulante (Letamendi, 1866, pp. 33-34, cursivas en el original).

Y no menos tajante se mostraba un año después en una extensa intervención ante el Ateneo Catalán en la que justificaba su radical oposición al evolucionismo debido precisamente al salto cualitativo que implicaba en el orden natural la incontrovertible existencia en el hombre del alma racional, para cuya demostración Letamendi proponía en un célebre "soliloquio" una suerte de "experimento interno" mediante el cual el 'yo' se revelaba invariablemente como "autor, actor, censor, espectador, teatro y drama; todo idéntico; todo uno; todo simple; inmaterial, activo y libre" (Letamendi, 1867, p. 71). En consonancia con estos planteamientos, Letamendi atacó frontalmente las doctrinas de Mata en las páginas de sus efímeros Archivos de la Medicina Española (1868) y tomó igualmente el "frontispicio" de El Pabellón Médico como blanco de sus críticas, calificándolo como una "sinopsis materialista" rebosante de "chambonería científica" y de "sandeces disfrazadas de principios" (Letamendi, 1907a, p. 265) $)^{13}$.

En cualquier caso, y más allá de las numerosas polémicas médico-filosóficas de la época, el discurso espiritualista del 'yo' también alcanzó otros ámbitos de reflexión más sectoriales pero igualmente significativos (y estrechamente relacionados) como los de la locura o la responsabilidad criminal. De hecho, las décadas de 1850 y 1860 asistieron a una notable proliferación de escritos -en la prensa médica, en tratados generales de clínica como los debidos a Juan Drumen (1862) y Tomás Santero (1866-1868) y en las obras de algunos autores más vinculados al naciente alienismo- en los que se defendía una concepción netamente espiritualista de la locura (Diéguez, 1998). Así, por ejemplo, un artículo publicado en 1858 en EI Siglo Médico señalaba que, aunque "las afecciones mentales han debido resentirse y sufrir las influencias que desde hace medio siglo viene obrando el materialismo sobre las ciencias médicas", la verdadera filosofía, el sentido común y la experiencia clínica enseñaban que "los celos, las ambiciones frustradas, los reveses de la fortuna y las pasiones violentas [...] hieren directamente al ser inteligente y lo dislocan", de manera que era "un absurdo suponer que siempre y en todas las ocasiones no se puedan explicar las aberraciones del entendimiento sin una causa material que explique su razón de ser" (De la Rosa, 1858, p. 316). Del mismo modo, el propio Nieto dedicó una serie de trabajos a combatir la noción según la cual "la locura depende precisamente de una lesión material del cerebro", y a alertar de las consecuencias de un dualismo excesivo que, postulando la incorruptibilidad esencial del alma, dejase el camino igualmente 
expedito a una atribución sistemática de la locura a un desorden primario de la actividad cerebral (Nieto y Serrano, 1868a). En su opinión, la locura consistía en una defectuosa objetivación del 'yo' que bien podía deberse a "causas accesorias, externas u ocasionales", pero que, debido a "la libre causalidad de los fenómenos de la inteligencia", no era sino una consecuencia del requerimiento impuesto al individuo de instituirse como "sujeto viviente" - esto es, como un "espíritu frente al cuerpo" -, por lo que su naturaleza era consustancial a la misma condición humana: "para que haya un loco solo es preciso que haya un hombre; y este hombre es cualquier hombre" (Nieto y Serrano, 1868 b, p. 596).

Entre los autores cuya producción o trayectoria profesional se ubicaba más de lleno en el campo de las enfermedades mentales, las tesis espiritualistas tuvieron una influencia muy acusada en figuras tan notables como el valenciano Juan Bautista Peset y Vidal (1821-1885) o el catalán Emilio Pi y Molist (18241892). Del primero, por ejemplo, es sabido que redactó una Patología psicológica (1859) que quedó inédita en gran parte, aunque algunos de sus capítulos fueron publicados posteriormente en El Siglo Médico (Rey González, 1985). En ellos, Peset partía de la naturaleza psíquica de los síntomas de la enajenación y de la "insuficiencia" de sus propios estudios anatomo-patológicos para abogar por una aproximación a la locura que pusiese en valor las aportaciones de la psicología "para penetrar en el intrincado laberinto de los fenómenos mentales" (Peset y Vidal, 1867, p. 88). Tras rechazar dogmáticamente el reduccionismo de "aqueIla escuela sensualista que consideraba los actos del espíritu como productos del cerebro o simples transformaciones de la sensación" (Peset y Vidal 1868a, p. 435), Peset daba a entender, eso sí, que la psicología requerida debía respetar la autonomía ontológica y la legitimidad epistémica de la conciencia. Y, por ello, sus preferencias se situaban sobre todo en la órbita espiritualista de Maine de Biran, Royer-Collard y el propio Cousin, cuya autoridad invocaba finalmente para definir la locura como una "pérdida de equilibrio o armonía entre las diversas operaciones del alma" y, en suma, como una "abolición del libre albedrío y de la personalidad" (Peset y Vidal, 1868b, p. 498).

Por su parte, Pi y Molist, más conocido por su dedicación a la renovación de la asistencia psiquiátrica y por su importante Proyecto médico razonado para la construcción del manicomio de Santa Cruz de Barcelona (1860) (Comelles, 2006, pp. 71-93), no dejó de expresar en uno de sus escasos trabajos teóricos sus dudas con respecto a la plausibilidad de una afectación parcial del psiquismo y del concepto mismo de monomanía recurriendo a un razonamiento que nos debe resultar familiar:

Puramente ilusoria es en el cuerdo la independencia de las facultades, e ilusoria también en el enajenado: en ambos resalta siempre la mancomunidad de la inteligencia, sensibilidad y voluntad; el trastorno de esta refleja el de las ideas, sentimientos y sensaciones. El yo patológico no puede contradecir al yo fisiológico, que uno y otro son idénticos, son la imagen viva de la unidad del alma (Pi y Molist, 1864 , p. 55 , cursivas en el original) ${ }^{14}$.

En este sentido, conviene recordar que la apelación a la unidad de la conciencia fue un argumento relativamente extendido entre los médicos para justificar su filiación espiritualista y rechazar de plano las posiciones organicistas. Así, por ejemplo, el médico catalán Francisco Castellví y Pallarés, que curiosamente se significó por defender en diversos escritos la existencia de la monomanía y el carácter patológico de las conductas suicidas (Rey González, 1984), no dudó en señalar la quiebra de la unidad del 'yo' como una de las consecuencias más inaceptables de la necesaria fragmentación del psiquismo implicada por las aproximaciones materialistas, esto es, como una "multiplicidad del yo que destruye el yo" (Castellví y Pallarés, 1859, p. 297, cursivas en el original). Por supuesto, en virtud de la "sujeción de la materia a leyes ciegas, fatales e inflexibles", la otra gran víctima del materialismo no era sino la libertad del individuo y el "fundamento mismo de la moralidad, la justicia y la sociedad" (Castellví y Pallarés, 1859, p. 299), por lo que no es casual que la cuestión del libre albedrío también tuviera un protagonismo muy destacado en las polémicas médico-filosóficas de la época y, muy especialmente, en los debates teóricos relacionados con la determinación de responsabilidad criminal (Diéguez, 2003).

A este respecto, la discusión más célebre se inició a finales de 1862 a raíz de la presentación a la Real Academia de Medicina de Madrid de la memoria "Pasión y locura: Distinción fundamental entre ambos estados" por parte del médico y filósofo madrileño Joaquín Quintana y Ollero (1814-1903). El texto de Quintana, que fue inmediatamente secundado por Nieto en su calidad de ponente de la Sección de Filosofía de la corporación (Nieto y Serrano, 1863b), constituye una de las aportaciones españolas de mayor nivel sobre las implicaciones médico-psicológicas del espiritualismo, $y$, en particular, sobre la naturaleza esencialmente irreductible de los fenómenos afectivos o la locura "en tanto hechos de conciencia". Así, tras descartar enfáticamente que las pasiones pudieran concebirse como "el resultado de las acciones orgánicas o como simples dependencias de la vida" debido al "abismo insondable" que media entre los "fenómenos representados y los representativos", Quintana pasaba a describir su actividad como "el desenvolvimiento en la conciencia de la categoría de finalidad", puntualizando acto seguido que "no implican, pero tampoco excluyen las funciones reflexivas y voluntarias" (Quintana, 1863a, pp. 214, 227 y 229). En la locura, por el contrario, la merma "total o parcial" de estas funciones era eviden- 
te de suyo, produciéndose una "enajenación de la personalidad" que impedía una atribución completa de responsabilidad a los actos del individuo. Ahora bien, a pesar de esta "distinción fundamental y constante" entre ambos fenómenos, su común inserción en ámbito de la conciencia - por definición "libre, autócrata y espontánea" - impedía confiar en la existencia de "signos exteriores y ciertos" con los que determinar la presencia de la enajenación mental, por lo que Quintana no vacilaba en afirmar que:

Esta cuestión es y será siempre cuestión de probabilidades y nada más, probabilidades que a la ciencia progresiva toca ampliar e indefinidamente extender, sin que le sea dable en ningún caso encontrar signos orgánicos o de otra especie perfectamente ciertos de locura, mientras que la espontaneidad sea espontaneidad y no se someta a leyes fatales y sea atributo de la naturaleza humana la libertad. Así pues, sea cualquiera el esmero que se ponga en la observación, siempre será posible encerrar en los manicomios a personas cuerdas como si fueran locos, y siempre habrá en medio de la sociedad una masa flotante de locos a quienes se rendirán las consideraciones de personas razonables y cuerdas (Quintana, 1863a, p. 265).

Poco menos que escandalizado por semejante declaración de escepticismo ante una cuestión de tanto peso, y no solo desde un punto de vista teórico sino también corporativo, Pedro Mata se apresuró a "combatir las ideas, principios y doctrinas consignadas en la memoria del señor Quintana" en un extenso discurso que pronunció en tres sesiones celebradas en la Academia en febrero y marzo de 1863 , en el que censuró su tratamiento "subalterno y desairado" de la fisiología, su énfasis en el carácter "vago y malseguro" de los signos exteriores de las pasiones y, sobre todo, su nula utilidad práctica - por moverse en un "terreno especulativo y psicológico puro" - en la determinación efectiva de responsabilidad (Mata, 1863b, pp. 203-204). Como era de esperar, Quintana se defendió reafirmándose en sus posiciones y atacando el determinismo subyacente a los planteamientos de Mata, a la vez que apelaba a la "buena fe de todo médico que haya tenido necesidad de declarar ante un tribunal" para certificar la falta de un "punto de apoyo sólido y objetivo" con el que avalar un diagnóstico cierto y concluyente de locura (Quintana, 1863b, p. 391).

Tras la participación en el debate de Nieto y del médico militar malagueño José María Santucho (ambos afines a las tesis de Quintana), la discusión prosiguió en septiembre del año siguiente con motivo de la celebración del Congreso Médico Español, cuya sexta sesión monográfica fue íntegramente dedicada al "criterio de la libertad moral en la perpetración del delito" y contó con nuevas intervenciones de Quintana, Nieto y Mata (secundado en esta ocasión por José Ametller y Federico Rubio) y hasta de Lorenzo Arrazola, Ministro de Gracia y Justicia (Martínez-Pérez, 1991). Mata se declaró entonces decidido a "reivindicar [para los médicos] la posesión de un terreno que exclusivamente nos pertenece" y a "defender los extensos, profundos y luminosos trabajos de los alienistas" en la materia, adelantando un total de siete bases o criterios con los que establecer la delimitación pericial de la "razón apasionada" frente a la "locura manifiesta"15. Pero, aparentemente insatisfecho con el resultado de la discusión, el médico catalán publicó en 1868 dos nuevas obras (tituladas respectivamente Criterio médico-psicológico para el diagnóstico diferencial de la pasión y la locura y De la libertad moral o libre albedrío) en las que compiló sus intervenciones en los debates en la Academia y el Congreso, sus dictámenes en diversos casos penales y civiles en los que había sido consultado (como los de Pedro Fiol y Juana Sagrera) e incluso una extensa contrarréplica a los últimos discursos de Quintana, Nieto y Santucho en la polémica de 1863.

Un tanto molestos por la extemporánea insistencia de Mata, Nieto y Quintana todavía respondieron desde las páginas de El Siglo Médico, reiterando su convicción de que los planteamientos "positivistas y materialistas" de aquel eran esencialmente incompatibles con la realidad sacrosanta e inviolable de la libertad moral: "la libertad -concluía Nieto en este sentido- es tan necesaria como el mismo sujeto consciente, y en la metafísica del objeto absoluto se hace imposible conservarla [...]. Por eso el señor Mata ha escrito un libro cuyo título exacto debiera ser Proceso contra la libertad moral" (Nieto y Serrano, 1869, p. 403). Por su parte, Quintana quiso llevar la cuestión a los fundamentos mismos de las posiciones de Mata, clamando contra su "vano empeño de hacer de la realidad psíquica una especie de reflejo sin entidad propia de la materia cerebral, [...] y de embutir violentamente y a golpe de mazo la psicología en el perímetro de la fisiología del cerebro" (Quintana, 1869, p. 421).

En síntesis, pues, puede decirse que salvaguardar el viejo dogma del libre albedrío y la responsabilidad moral fue una de las razones que movieron a un buen número de médicos españoles a abrazar el espiritualismo psicológico durante gran parte del siglo XIX, aunque para ello incurrieran en dificultades teóricas y prácticas a la hora de reafirmar su competencia en la determinación pericial del crimen y la locura. Y, de hecho, solo con la circulación en las décadas finales de la centuria de los planteamientos organicistas y abiertamente deterministas de doctrinas como la teoría de la degeneración y la antropología criminal, la espinosa cuestión de la libertad moral dejó de tener una relevancia significativa en las consideraciones teóricas de los médicos españoles en torno a la conducta y la experiencia desviada (Huertas \& Martínez-Pérez, 1993). 


\section{CIENCIA Y CREENCIA}

Como es sabido, el clima de apertura y libertad de expresión que caracterizó el Sexenio Revolucionario (1868-1874) propició una creciente difusión de los planteamientos naturalistas y monistas inherentes a diversas doctrinas y corrientes de pensamiento como el trasformismo darwinista, el positivismo comtiano y spenceriano o el materialismo de origen germánico (Núñez Ruiz, 1975, pp. 37-41; Heredia Soriano, 1989, pp. 410-411). Pocos años después, los cenáculos intelectuales españoles empezaban a conocer y asimilar los métodos y resultados de la nueva psicología experimental y fisiológica, cuyos pioneros europeos aspiraban a fundar nada menos que un conocimiento científico-natural del psiquismo, a abandonar la primacía epistémica de la introspección y, en suma, a emancipar a la disciplina del ámbito del discurso filosófico (Mueller, 1963, pp. 319-332). Así, mientras publicaciones de prestigio como la Revista Europea o la Revista Contemporánea daban a conocer en la década de 1870 las obras de autores como Wundt, Ribot - Spencer, los manuales escolares de psicología de Francisco Giner de los Ríos (1878) o Urbano González Serrano (1880) se hacían eco - tal como se anunciaba en el mismo subtítulo de la segunda edición de las Lecciones de Giner- de "los últimos progresos de la antropología y la fisiología psicológica", e incluso los polémicos Ensayos de psicología celular de Ernst Haeckel eran reunidos en una versión castellana prologada por el anatomista Peregrín Casanova y aparecida en Valencia en $1882^{16}$.

Como pone de manifiesto el gran número de debates mantenidos en aquellos años en el Ateneo de Madrid en los que se abordaron cuestiones de interés psicológico ${ }^{17}$, la irrupción del espíritu antimetafísico - cuando no abiertamente materialista - impulsado por el positivismo y las nuevas teorías psico-fisiológicas afectaba de lleno a los presupuestos antropológicos encarnados durante décadas en el discurso espiritualista del 'yo', por lo que no es casual que, junto al evolucionismo, la psicología constituyera en España uno de los escenarios cardinales en los que se dirimió la confrontación que acompañó al despliegue de la nueva ciencia positiva y experimental (Núñez Ruiz, 1975, p. 15; Abellán, 1984, pp. 515-517; Blanco \& Castro, 2005). Naturalmente, e igual que ocurrió con el darwinismo (Glick, 2011), las implicaciones de este nuevo clima intelectual para el discurso psicológico tradicional fueron advertidas de inmediato por los representantes más destacados de todas aquellas escuelas que, sucesiva pero ininterrumpidamente, lo habían sostenido hasta entonces. Y, en este sentido, es muy revelador que la crítica del materialismo y del supuesto monista presuntamente alentado por el positivismo y la nueva psicología 'científica' reuniera entonces en un mismo bando a espiritualistas como
Patricio de Azcárate, neocatólicos como el Padre Zeferino González, krausistas como Francisco de Paula Canalejas y hasta hegelianos como el sevillano Antonio María Fabié ${ }^{18}$.

Retrospectivamente, estas resistencias son muy significativas con respecto al importantísimo papel ideológico desempeñado por el discurso del 'yo' en la cultura española de buena parte del siglo XIX. Desde luego, no cabe duda de que el 'yo' sustancial, unitario y activo de la psicología espiritualista decimonónica operó como un axioma destinado a contrarrestar las fuertes tendencias de naturalización, reducción y fragmentación del psiquismo implícitas en la aproximación objetivante, analítica y experimental propia de la ciencia moderna (Goldstein, 2005, pp. 324-329). $\mathrm{Y}$, por ese motivo, el sensualismo y la frenología primero, y la psicología fisiológica después, aparecieron a los ojos de un gran número de españoles cultos del siglo XIX como una serie de doctrinas particularmente aberrantes cuyos postulados resultaba imperioso combatir, pues sus consecuencias no eran sino una completa degradación moral del hombre y un angustioso desencantamiento del mundo en medio de las inevitables zozobras de la vida. Así, por ejemplo, el jurista y arabista José Moreno Nieto, uno de los últimos representantes españoles del espiritualismo ecléctico y destacado oponente del positivismo en los debates del Ateneo, alertaba en una fecha tan tardía como 1876 sobre los procedimientos de la nueva psicología fisiológica y las implicaciones de sus supuestos epistemológicos en unos términos que resultan sumamente reveladores:

Al dirigir la mirada sobre el mundo que nos ofrece, se advierten en él vacíos inconmensurables cuya contemplación pone en el espíritu no sé qué estremecimiento o estupor, o impresión, que se parece a la que dejan en el hombre las tinieblas y la noche fría. ¿Qué concepción puede dar esa filosofía de la vida? ¿Cómo resolverá el problema de la existencia universal? [...]

La inteligencia es sensación trasformada, acumulada, repetida con más o menos vehemencia, y luego sumada o generalizada. La conciencia es la totalidad de las sensaciones ya elaboradas reducidas a la unidad. ¡Qué serie de hipótesis y supuestos imaginarios! ¡Qué de saltos mortales, qué de absurdos! [...] Después de quitado Dios, y la vida moral, y la inmortalidad del alma, dejad que esa doctrina inspire a los hombres y los dirija. ¡Qué horror, señores! Pronto el mundo presentaría aquel cuadro aterrador de desolación y espanto que nos pinta Byron en las tinieblas (Moreno Nieto, 1876 , pp. $17-25$ y 29 ).

Pero, en un sentido más amplio, el discurso del 'yo' y el consenso espiritualista en el que se sustentó durante décadas también expresaban el estado de una cultura que, en líneas generales, todavía no había escindido hechos y valores ni asumido la prioridad gnoseológica de las aportaciones de la ciencia natural, por lo que, en 
última instancia, su relevancia histórica debe situarse antes que nada en el marco del largo, complejo y azaroso proceso de implantación de la nueva cosmovisión emanada del despliegue de la ciencia moderna. Y, en este sentido, nada mejor que recordar el propio testimonio de Patricio de Azcárate, que todavía en 1853 podía afirmar con total confianza que:

jamás las luces pueden perjudicar a la verdad; y siendo la religión toda verdad, jamás pueden perjudicarla los conocimientos filosóficos. Lo cierto es que, cuanto mayores han sido los descubrimientos

\section{NOTAS}

1 Sobre las ideas psicológicas de Mata pueden consultarse Doménech (1980) y la monografía de López Fernández (1993). Véase también la influyente apreciación de Mata por Menéndez Pelayo (1992, Vol. 2, pp. 1265-1269).

2 Sobre la vida y obra de Patricio de Azcárate puede consultarse su muy documentada entrada en el Proyecto Filosofía en Español (http://www.filosofia.org/ave/001/a163.htm) [consultado el 25/09/2012]

3 Del mismo modo lo calificó en su momento Eloy Bullón, que en un artículo aparecido poco después de la muerte de Campoamor en La Ilustración Española y Americana lo describía como un "partidario ardiente del espiritualismo y enemigo irreconciliable de toda doctrina que tienda a rebajar al hombre o a reducir al orden material y visible la esfera de sus conocimientos" (Bullón, 1902, p. 91). En cualquier caso, la filiación idealista de Campoamor es clara en su obra Lo absoluto (1865), que, en irónica expresión de Méndez Bejarano (1929, p. 509), "trae demasiado a la memoria a Schelling".

4 "Alma". En: Enciclopedia Española del Siglo Diez y Nueve, Vol. 10, Madrid, Imprenta y Librería de Ignacio Boix, 1845, pp. 19-24, p. 20.

5 "Alma". En: Enciclopedia Moderna, Vol. 2, Madrid, Imprenta y Librería de Francisco de Paula Mellado, 1851, cols. 143-151, col. 149.

6 "Espíritu". En: Enciclopedia Moderna, Vol. 17, Madrid, Imprenta y Librería de Francisco de Paula Mellado, 1852, cols. 987-993, cols. 988-990 (cursivas en el original).

7 “Materialismo". En: Enciclopedia Moderna, Vol. 27, Madrid, Imprenta y Librería de Francisco de Paula Mellado, 1854, cols. 207209, col. 208 (cursivas en el original).

8 Mucho antes que ellos, el propio Jaime Balmes ya había pronunciado estos mismos cargos contra Cousin y su escuela ecléctica en una de sus "Cartas a un escéptico en materia de religión" publicada en 1844 en su quincenal La Sociedad (Balmes, 1844).

9 En Francia, por ejemplo, el mismo Victor Cousin alertó en repetidas ocasiones de la tentación materialista que acechaba a los estudiantes de medicina, por lo que recomendaba vivamente que recibieran una formación filosófica previa que les iniciara en las saludables verdades del espiritualismo: "Et l'élève en médecine, que deviendra-t-il, je vous prie, au milieu de toutes en ciencias naturales, tanto más evidentes han resultado las interpretaciones bíblicas, dadas por la Iglesia a los libros santos; y cuantos más progresos se han hecho en el conocimiento de Dios, del hombre y de la naturaleza por la razón, tanto más se han afianzado las verdades fundamentales de la religión, como la existencia de Dios, la de su providencia, la espiritualidad e inmortalidad del alma, y la inmutabilidad del principio moral (Azcárate, 1853, pp. 15-16)

ces études qui le plongent au foyer même de la vie matérielle, si, avant d'aborder ces périlleuses études, il n'est pas convaincu qu'il y a des êtres qui peuvent exister très réellement alors même qu'ils ne tombent ni sous le microscope ni sous le scalpel?" (Cousin, 1850, p. 100). Y en España, todavía en 1874 la propia Concepción Arenal denunciaba desde las páginas de $L a$ Voz de la Caridad la "tendencia materialista, y casi estamos por decir brutal" de los médicos, tendencia que, en su opinión, les imposibilitaba para liderar la gestión institucional de la locura (Arenal, 1900, p. 22).

10 Entre estas obras destacan la célebre La medicina de las pasiones (1842) de Jean-Baptiste Félix Descuret, De la fisiología humana y la medicina en sus relaciones con la religión cristiana, la moral y la sociedad (1843) de François Devay o los Pensamientos de un creyente católico, o consideraciones filosóficas, morales y religiosas sobre el materialismo moderno, el alma de las bestias, la frenología, el suicidio, el duelo y el magnetismo animal (1849) de Pierre-Jean-Corneille Debreyne.

11 La portada de El Pabellón Médico incluía la siguiente declaración de principios: "Filosofía positiva. Método analítico. [...] La materia es activa y sigue las mismas leyes en el mundo inorgánico que en el orgánico. La vida es un efecto complejo debido al concurso de varias causas todas naturales. [...] La enfermedad es un estado del ser viviente debido siempre a alteraciones de los sólidos, líquidos o gases". Y, en su primer número, la revista declaraba que se proponía "trabajar con todo el ardor y profundidad de nuestras creencias para desembarazar a nuestra ciencia de todo lo que tenga de teológico y metafísico, declarando como impropio de ella todo problema que tienda a resolver lo esencial, lo infinito y lo absoluto como indemostrable, como superior a la limitada inteligencia humana, y reduciendo su perímetro a todo lo que yazga bajo el dominio de la inducción y la experiencia" ("Filosofía médica", El Pabellón Médico, 1, 1861, pp. 1-2).

12 Sobre la obra de Letamendi, véanse Guy (1985, pp. 264-266) y Carreras y Artau (1952, pp. 131-380).

13 El Pabellón replicó de inmediato con un extenso artículo en el que calificaba las opiniones de Letamendi como "cabriolas pedantescas en el trapecio metafísico", a la vez que insistía en que su programa no era sino una proclama estrictamente científica y progresista que, en todo caso, sólo daba "la espalda a la metafísica como ciencia especulativa lanzada [...] en pos del absoluto, de las esencias, de los orígenes, de los principios 
aprióricos [sic] y de las ontologías quiméricas" (La Redacción, “El programa de El Pabellón Médico", El Pabellón Médico, 8, 1868, pp. 133-134). Irritado por el anonimato de la réplica, Letamendi volvió a la carga semanas después con un nuevo artículo dirigido esta vez al propio Mata ("Una lección al Doctor Mata-Siete"), en el que le acusaba abierta y enfáticamente de "negar positivamente la existencia real del espíritu humano" (Letamendi, 1907b, p. 283).

14 Por si quedaban dudas, Pi no vaciló en incluir años después en sus celebrados Primores del Don Quijote en el concepto médico-psicológico (1886) una sentida "profesión de fe" en el espiritualismo ("al que se jactan algunos de haber dado ya, después que al vitalismo, la estocada de remate"), reconociendo explícitamente que sus convicciones ya no casaban "con las corrientes a que quieren muchos lanzar la nave de la ciencia frenopática" (Pi y Molist, 1886, p. 20). Sobre la recepción en España del concepto de monomanía, cuya aceptación general comenzó a declinar justamente a partir del trabajo de Pi, puede consultarse Martínez-Pérez (1995).

15 Entre ellos mencionó (1) la existencia de "razón moral" o de un motivo para la acción, (2) la continuidad biográfica del acto, (3) su coherencia con el conjunto de la vida psíquica, (4) su grado de planificación, (5) su relación con las "condiciones orgánicas" del sujeto, (6) su focalización en una determinada persona u objeto y (7) la conexión del impulso agresivo con los hábitos previos del individuo (Actas de las sesiones del Congreso Médico Español celebrado en Madrid en Setiembre de 1864, Madrid, Imprenta de José Ma Ducazcal, 1865, pp. 562-590). Véase Carreras y Artau (1952, pp. 63-77) para una exposición más detallada de los criterios sucesivamente propuestos por Mata.
16 La publicación de esta obra del célebre biólogo y filósofo alemán provocó una airada reacción por parte de pensadores espiritualistas y neocatólicos como el catedrático de Metafísica de la Universidad de Zaragoza Antonio Hernández Fajarnés, que en 1883 le dedicó el primero (y único) de sus Estudios críticos sobre la filosofía positivista. Sobre la obra de Haeckel y el estudio de Fajarnés puede verse Quintana Fernández (1999).

17 Sobre este asunto puede consultarse el documentado trabajo de Mateos, Travieso, Sánchez \& Blanco (1997).

18 De hecho, todos estos autores -a los que hay que añadir al joven González Serrano, que dedicó su tesis doctoral al Estudio de los principios de la moral con relación a la doctrina positivista (1871) - publicaron en la primera mitad de la década de 1870 sendas refutaciones del positivismo y el materialismo cuyo denominador común era, en clara continuidad con las críticas anteriores al sensualismo o la frenología, la denuncia de su carácter esencialmente subversivo para la fundamentación racional de la libertad y, por tanto, de la vida moral, social y religiosa. Así, por ejemplo, el Padre Zeferino González explicaba en una serie de artículos publicados en 1872 en la revista católica La Defensa de la Sociedad que el "fatalismo" y el "egoísmo" eran las consecuencias naturales de todas aquellas doctrinas para las que "el alma racional o espiritual, como sustancia distinta y superior al cuerpo, es una quimera; el pensamiento, una afección o modificación del cerebro; y la libertad o libre albedrío, una decepción" (citado por Núñez Ruiz, 1975, p. 69).

\section{BIBLIOGRAFÍA}

Abellán, José Luis (1984), Historia crítica del pensamiento español, Vol. 4: Liberalismo y romanticismo (1808-1874), Madrid, Espasa-Calpe.

Albares Albares, Roberto (2005), "El proyecto filosófico espiritualista de Nicomedes Martín Mateos (1806-1890)". En: Jiménez García, Antonio; Orden Jiménez, Rafael V. y Agenjo Bullón, Xavier (eds.), Nuevos estudios sobre historia del pensamiento español. Actas de las V Jornadas de Hispanismo Filosófico, Madrid, Fundación Ignacio Larramendi / Asociación de Hispanismo Filosófico, pp. 183-201.

Arenal, Concepción (1900), "Ley de dementes". En: Artículos sobre beneficencia y prisiones, Vol. 3, Madrid, Librería de Victoriano Suárez, pp. 21-26.

Azcárate, Patricio de (1853), Veladas sobre la filosofía moderna, Madrid, Imprenta y Estereotipia de M. Rivadeneyra.

Azcárate, Patricio de (1861), Exposición histórico-crítica de los sistemas filosóficos modernos y verdaderos principios de la ciencia, Madrid, Establecimiento Tipográfico de D. Francisco de Paula Mellado.

Balmes, Jaime (1844), "Carta décima a un escéptico en materia de religión”, La Sociedad, 2, pp. 166-171.
Blanco, Florentino y Castro, Jorge (2005), “La significación cultural de la psicología en la España restaurada". En: Jiménez García, Antonio; Orden Jiménez, Rafael V. y Agenjo Bullón, Xavier (eds.), Nuevos estudios sobre historia del pensamiento español. Actas de las V Jornadas de Hispanismo Filosofico, Madrid, Fundación Ignacio Larramendi / Asociación de Hispanismo Filosófico, pp. 293-307.

Bueno, Gustavo (2003), "Campoamor y Ortega". En: Campoamor, Ramon de, Obras filosóficas, Oviedo, Pentalfa, Vol. 1, pp. 9-13.

Bullón, Eloy (1902), “Campoamor, filósofo”, La Ilustración Española y Americana, 46 (6), pp. 90-91.

Campoamor, Ramón de (1855), El personalismo. Apuntes para una filosofía, Madrid, Imprenta y Estereotipia de M. Rivadeneyra.

Canalejas, Francisco de Paula (1861), "Del estado de la filosofía en las naciones latinas", La América, 5 (11), pp. 8-11.

Carpintero, Heliodoro (2004), Historia de la psicología en España, Madrid, Pirámide.

Carreras y Artau, Tomás (1952), Médicos-filósofos españoles del siglo XIX, Barcelona, CSIC. 
Castellví y Pallarés, Francisco (1859), “Ontología y ontologismo: Materia y materialismo (II)", El Siglo Médico, 6, pp. 297-299.

Comelles, Josep M. (2006), Stultifera navis: La locura, el poder y la ciudad, Lleida, Milenio.

Cousin, Victor (1850), CEuvres de M. Cousin. Cinquième Série: Instruction publique, Vol. 2, París, Pagnerre.

De la Rosa, Enrique (1858), “Locura”, El Siglo Médico, 5, pp. 293294, 316.

Diéguez, Antonio (1998), "Psicologismo versus organicismo en la psiquiatría española del siglo XIX", El Médico: Profesión y Humanidades, 674, pp. 70-77.

Diéguez, Antonio (2003), “El problema del libre albedrío en el alienismo español". En: Fuentenebro, Filiberto; Huertas, Rafael y Valiente, Carmen (eds.), Historia de la psiquiatría en Europa: Temas y tendencias, Madrid, Frenia, pp. 137-146.

Doménech, Edelmira (1980), "Las ideas de Pedro Mata en el campo de la psicología de su tiempo", Asclepio, 32, pp. 137-150.

Glick, Thomas F. (2011), Darwin en España, Valencia, Publicacions de la Universitat de València.

Goldstein, Jan E. (2005), The Post-Revolutionary Self: Politics and Psyche in France, Cambridge MA, Harvard University Press.

González, Zeferino (1864), Estudios sobre la filosofía de Santo Tomás, Vol. 1, Manila, Establecimiento Tipográfico del Colegio de Santo Tomás.

Guy, Alain (1985), Historia de la filosofía española, Barcelona, Anthropos.

Heredia Soriano, Antonio (1982), Política docente y filosofía oficial en la España del siglo XIX: La era isabelina (1833-1868), Salamanca, Instituto de Ciencias de la Educación.

Heredia Soriano, Antonio (1989), "La filosofía". En: Juretschke, Hans (coord.), La época del romanticismo (1808-1874). Historia de España Menéndez Pidal, Vol. XXXV, Madrid, Espasa-Calpe, pp. 329-420.

Huertas, Rafael y Martínez-Pérez, José (1993), “Disease and crime in Spanish positivist psychiatry", History of Psychiatry, 4, pp. 459-481.

Jiménez García, Antonio (1992), "El espiritualismo de Nicomedes Martín Mateos (1806-1890)". En: Heredia Soriano, Antonio (ed.), Exilios filosóficos de España. Actas del VII Seminario de Historia de la Filosofía Española e Iberoamericana, Salamanca, Universidad de Salamanca, pp. 231-234.

Laverde, Gumersindo (1859), "Biblioteca de filósofos ibéricos. Prospecto", Revista de Instrucción Pública, Literatura y Ciencias, 4, pp. 381-384.

Letamendi, José de (1866), Discurso sobre los elementos generales de ciencia con aplicación al método en medicina, Barcelona, Establecimiento Tipográfico de Narciso Ramírez y Compañía.

Letamendi, José de (1867), Discurso sobre la naturaleza y el origen del hombre, Barcelona, Establecimiento Tipográfico de Narciso Ramírez y Compañía.
Letamendi, José de (1907a), “El frontispicio de El Pabellón Médico o el Alcorán de los positivistas madrileños". En: Obras Completas, Vol. 5, Barcelona, Establecimiento Tipográfico de F. Rodríguez Ojeda, pp. 265-272 (original de 1868).

Letamendi, José de (1907b), "Una lección al Doctor Mata-Siete”. En: Obras Completas, Vol. 5, Barcelona, Establecimiento Tipográfico de F. Rodríguez Ojeda, pp. 273-299 (original de 1868).

López Fernández, Mạ Nieves (1993), La psicología en la obra de Pedro Mata y Fontanet, Valladolid, Universidad de Valladolid.

López Piñero, José María (ed.) (1992), La ciencia en la España del siglo XIX, Madrid, Marcial Pons (AYER, Vol. 7).

Martín Mateos, Nicomedes (1853), Breves consideraciones sobre la reforma de la filosofía, Salamanca, Imprenta de Juan José Morán y Compañía.

Martín Mateos, Nicomedes (1861), El espiritualismo: Curso de filosofía, Vol. 1, Madrid, Establecimiento Tipográfico de Francisco de Paula Mellado.

Martínez-Pérez, José (1995), "Problemas científicos y socioculturales en la difusión de una doctrina psiquiátrica: La introducción del concepto de monomanía en España (1821-1864)". En: Arquiola, Elvira y Martínez-Pérez, José (eds.), Ciencia en expansión. Estudios sobre la difusión de las ideas científicas y médicas en España (siglos XVIII-XX), Madrid, Editorial Complutense, pp. 490-520.

Martínez-Pérez, José (1991), "La discusión sobre la libertad moral del delincuente en el Congreso Médico Español de 1864", en: Actas del V Congreso Internacional de la Sociedad Española de Historia de las Ciencias y las Técnicas, Vol. 1, pp. 633-648.

Mata y Fontanet, Pedro (1857), Tratado de medicina y cirugía legal, 3 a ed., Madrid, Carlos Bailly-Baillière.

Mata y Fontanet, Pedro (1858), Filosofía española: Tratado de la razón humana con aplicación a la práctica del Foro, Madrid, Carlos Bailly-Baillière.

Mata y Fontanet, Pedro (1859a), “Cartas al Dr. Nieto sobre su crítica de mi Tratado de la razón humana", El Siglo Médico, 6, pp. 1113, 38-39, 63-65, 83-84.

Mata y Fontanet, Pedro (1859b), Hipócrates y las escuelas hipocráticas, Madrid, Imprenta de Manuel Rojas.

Mata y Fontanet, Pedro (1860), Doctrina médico-filosófica española sostenida durante la gran discusión sobre Hipócrates y las escuelas hipocráticas en la Academia de Medicina y Cirugía de Madrid y en la prensa médica, Madrid, Carlos Bailly-Baillière.

Mata y Fontanet, Pedro (1863a), "Nuestro programa en litigio", El Pabellón Médico, 3, pp. 28-30.

Mata y Fontanet, Pedro (1863b), "Discurso pronunciado por el Dr. D. Pedro Mata en la Real Academia de Medicina de Madrid", La España Médica, 8, pp. 135-136, 156-157, 171-173, 186-188, 201-204, 221-223, 233-235, 268-269, 284-285.

Mateos, Ana Isabel; Travieso, David; Sánchez, Ramón y Blanco, Florentino (1997), "El Ateneo de Madrid: una caja de resonancia para el debate sobre las relaciones entre ideología y discurso psicológico". En: Blanco, Florentino (ed.), Historia de la psicolo- 
gía en España. Desde una perspectiva socio-institucional, Madrid, Biblioteca Nueva, pp. 69-108.

Menéndez Pelayo, Marcelino (1992), Historia de los heterodoxos españoles, Madrid, CSIC (original de 1882).

Méndez Bejarano, Mario (1929), Historia de la filosofía en España hasta el siglo XX, Madrid, Renacimiento.

Moreno Nieto, José (1876), El problema filosófico: Discurso pronunciado el 3 de noviembre de 1876 en el Ateneo de Madrid, Madrid, Empresa del Boletín Oficial del Ateneo.

Mueller, Fernand-Lucien (1963), Historia de la psicología, México DF, Fondo de Cultura Económica.

Nieto y Serrano, Matías (1854), “Filosofía médica: Rápida reseña de su estado actual”, El Siglo Médico, 1, pp. 1-2.

Nieto y Serrano, Matías (1858), "Tratado de la razón humana con aplicación a la práctica del foro, por el Dr. Pedro Mata", El Siglo Médico, 5, pp. 391-392, 408-410.

Nieto y Serrano, Matías (1859), "Contestación al Dr. Mata sobre su crítica de mi crítica”, El Siglo Médico, 6, pp. 167-169, 174-175, 183-184, 192-193, 206-208, 216-217.

Nieto y Serrano, Matías (1862), “¿Es inmejorable el estado actual de la medicina? (IV)", El Siglo Médico, 9, pp. 817-820.

Nieto y Serrano, Matías (1863a), "Contestación a un "no contesto"”, El Siglo Médico, 10, pp. 65-67.

Nieto y Serrano, Matías (1863b), “Dictamen de la Sección de Filosofía sobre la memoria de Don Joaquín Quintana titulada 'Pasión y locura'", El Siglo Médico, 10, pp. 275-278.

Nieto y Serrano, Matías (1868a), “¿Depende la locura precisamente de una lesión material del cerebro?”, El Siglo Médico, 15, pp. 547-549.

Nieto y Serrano, Matías (1868b), “De cómo procede la locura de la mutua relación entre la libertad y las leyes psíquico-somáticas", El Siglo Médico, 15, pp. 595-597.

Nieto y Serrano, Matías (1869), "De la libertad moral: Breve réplica a un libro del señor Don Pedro Mata", El Siglo Médico, 16, pp. 272-275, 289-295, 305-308, 321-323, 337-339, 369-372, 385$388,401-403$

Nieto y Serrano, Matías (1902), Vejeces, Madrid, Establecimiento Tipográfico de E. Teodoro.

Novella, Enric J. (2010), "La política del yo: Ciencia psicológica y subjetividad burguesa en la España del siglo XIX", Asclepio, LXII (2), pp. 453-481.

Novella, Enric J. (2012), "La psicología en las aulas: Ciencia y subjetividad en la educación secundaria española del siglo XIX". En: López-Ocón, Leoncio; Aragón, Santiago y Pedrazuela, Mario (eds.), Aulas con memoria. Ciencia, educación y patrimonio en los institutos históricos de Madrid (1837-1936), Madrid, CEIMES/CSIC/ Comunidad de Madrid, pp. 309-320.

Núñez Ruiz, Diego (1975), La mentalidad positiva en España: Desarrollo y crisis, Madrid, Túcar.
Pelayo, Francisco (1999), Ciencia y creencia en España durante el siglo XIX: La paleontología en el debate sobre el darwinismo, Madrid, CSIC.

Peset y Vidal, Juan Bautista (1867), "Estudios psicológicos", El Siglo Médico, 14, pp. 87-89.

Peset y Vidal, Juan Bautista (1868a), "Estudios históricos y filosóficos de la enagenación mental”, El Siglo Médico, 15, pp. 433-435.

Peset y Vidal, Juan Bautista (1868b), "Teoría del delirio y la enagenación y su explicación más satisfactoria”, El Siglo Médico, 15, pp. 497-500.

Pi y Molist, Emilio (1864), Apuntes sobre la monomanía, Barcelona, Imprenta del Diario de Barcelona.

Pi y Molist, Emilio (1886), Primores del Don Quijote en el concepto médico-psicológico, Barcelona, Imprenta Barcelonesa.

Quintana, Joaquín (1863a), "Pasión y locura: Distinción fundamental entre ambos estados", El Siglo Médico, 10, pp. 212-215, 227$230,244-247,261-265$

Quintana, Joaquín (1863b), "Discurso pronunciado sobre "La pasión y locura" en la Real Academia de Medicina de Madrid", El Siglo Médico, 10, 341-344, 357-359, 373-375, 390-392.

Quintana, Joaquín (1869), "Otra nueva respuesta al libro de la libertad moral escrito por el doctor Sr. D. Pedro Mata", El Siglo Médico, 16, 417-422.

Quintana Fernández, José (1999), “La 'psicología celular' de E. Haeckel en España. La crítica de A. Hernández Fajarnés (1883)”, Revista de Historia de la Psicología, 3/4, pp. 351-366.

Ramírez, Remigio (1851), "Nociones generales de filosofía”. En: Instrucción para el pueblo. Cien tratados, Vol. 2, Madrid, Francisco de Paula Mellado, cols. 1752-1760.

Ramos, Tomás (1954), "La polémica hipocrática en la medicina española del siglo XIX", Archivo Iberoamericano de Historia de la Medicina y Antropología Médica, 6, pp. 115-161.

Rey González, Antonio (1984), “Clásicos de la psiquiatría española del siglo XIX (V): Francisco Castellví y Pallarés (18121879)", Revista de la Asociación Española de Neuropsiquiatría, 4, pp. 103-116.

Rey González, Antonio (1985), “Clásicos de la psiquiatría española del siglo XIX (IX): Juan Bautista Peset y Vidal (18211885)", Revista de la Asociación Española de Neuropsiquiatría, 5, pp. 87-98.

Riera, Juan (1977), “Matías Nieto y Serrano (1813-1902) y la medicina romántica". En: Actas del V Congreso Nacional de la Sociedad Española de Historia de la Medicina, Vol. 3, Madrid, SEHM, pp. 367-381.

Serrano García, Rafael (2001), El fin del Antiguo Régimen (18081868): Cultura y vida cotidiana, Madrid, Síntesis.

Villacorta Baños, Francisco (1993), Culturas y mentalidades en el siglo XIX, Madrid, Síntesis. 